\title{
The Continuous Auditing
}

\author{
Evelio Hernandez Pascual \\ Facultad de Ciencias de la Computación y las Telecomunicaciones, Facultad Politecnica, UAGRM, Santa Cruz, Bolivia
}

\begin{abstract}
An analysis of the CA (continuous auditing) technique presented in this article to speed up processes oriented Audit review of controls, risk management and detection: fraud, suspicious and unusual transactions, errors, etc. Applications presented are based on the use of CAATs (computer assisted audit techniques), developed cases with the Case ware IDEA software version 10.1.2 are discussed and some processes and the way in which it has developed the corresponding application are illustrated. The solutions are implemented using scripts and the importance they have on the implementation a solution CA stands, it is stressed that to develop simple applications using scripts do not need to be a programmer or specialist in any branch computing, however, it is preferable help prior knowledge of programming, but it is necessary the auditor has access to data, whether because of security reason or another do not have access to data is not possible to implement applications CA.
\end{abstract}

Key words: Continuous auditing, scripts, computer assisted audit techniques, virtual field.

\section{Introduction}

Each day response time to requests and questions from the upper levels of the company are reduced, risk control is part of the work of the auditor [1], the pace of life makes audits also provide faster responses, so that the evidence and irregularities can be corrected and punished as soon as possible [2]. The application of CAATs (computer assisted audit techniques) [3] facilitates the streamlining of these processes and also allows you to review, in many cases, $100 \%$ of transactions of an entity, which gives a much more reliable character to process, as the entire population of data and not a sample thereof is analyzed.

To expedite reviews and audits with the implementation of CAATs, scripts or macros are used, enabling the automation of the task as such, this allows the auditor immediately engaged in the analysis of the results and the corresponding report without having used previously the job of creating a project, import the data, control and perform substantive tests to obtain the corresponding evidence [4]. The processes taking place in the company

Corresponding author: Evelio Hernandez Pascual, M.Sc., lecturer, teacher, consultand, research field: CAATs application. routinely, for example: daily, once a week, once a month, etc. are candidates to be automated, as they have been developed with the corresponding CAATs tool has verified its functioning and you have confidence which can become part of a script, therefore revisions to payroll salary, verification interest calculation, verification of transactions in a warehouse, processes linked to purchases, sales, determination of illicit profits, money laundering, etc. can be included in the audit automation, entering a stage of the audit known as CA (continuous auditing) $[1,5]$. This concept has been used since the last century and it should be noted that it is not yet implemented in all its magnitude [6, 7].

The paper is organized as follows: first the AC implementation based on the use of macros or scripts explained, then the essential characteristics of some applications of the AC is exposed, finally the benefits of AC mentioned and set out the conclusions.

\section{Automating Audit Processes}

The CA is based on the automation of processes Audit and for that purpose, called scripts or macros are used. A macro is set as a set of commands that are to work together in order to execute a task automatically. The use of macros allows to enter a 
level of automation of processes in which the user can access the code through the corresponding Editor and modify it, can also interact with the application through dialog boxes, Input Box. MsgBox and other objects [8]. The code can be purchased for history, for the Global Project Diagram, on the other Macro or can type directly in the Editor IDEAScript. This technology facilitates process large volumes of data and sends alarms when necessary, but it must be a scheduled job for which suggests [9]:

- Know the organizational structure of the company;

- Know the business units and their critical processes;

- Evaluate environment Information Technology;

- Identify risks and controls;

- Categorize risks (High, Medium, Low);

- Define the objectives of the audit;

- Obtain authorization for implementation.

Using the CA (continuous auditing) the effectiveness of controls is maintained because being tested systematically and reporting the results after the occurrence of an event or shortly after it while with the traditional or classical Auditing this effectiveness increases after completing the work and delivering the recommendations but decreases until the next audit. The CA can detect anomalies, Irregularities, fraud [10], etc. making it easy to quickly make adjustments and also punish those involved in the events.

The study by PwC (PricewaterhouseCoopers) entitled "State of the internal audit profession 2006" states that "solutions continuous auditing are prized by executives audit as a means to shorten the audit cycle and provide audits risk and control assurance to key stakeholders in a more timely manner.”

As discussed above have developed several applications Audit Continuous using Caseware IDEA, this software on as they are by testing it generates the corresponding script to which the auditor can access later put it as part of a larger macro and even modify it, therefore there is no need to develop a programming code from scratch.

Data users can be on different software platforms such as: Excel, Access, Oracle, SQL, PDF, text, SAP, etc. the software will make the corresponding import with the guarantee that these data cannot be changed, work with software for Data Analysis which guarantees non-modification thereof and includes the ease of using scripts to ensure continuous auditing.

Any process of audit or review data begins with the creation of a project, then the data to IDEA or to the software you are using are imported [11] and then the corresponding tests are implemented, among which we highlight extractions, stratifications, sampling, graphics, pivot table, duplicate detection, detection of omissions, union database, database comparison, abstracts and also the use of arithmetic functions, financial date, [12] etc.

The results can be issued in the form of reports, can be graphed, mail, export and also can comment explaining the methods used and even serve as a memory aid for the audit report.

\section{Applications}

When there are several tasks that belong to the same process can create a dialog box with buttons, which makes the function module or main program and from which calls each of the tasks, each task will be developed individually and at the end returns to the main program. It is illustrated with an example for an application related to payroll audit [13]:

Macro code includes managing the dialog box and the solution to each of the tasks. Each button is responsible for calling a specific function, for example, the last button produces a call to the Ghosts function, which is responsible for verifying whether there are people who do not belong to the company and appear in the form and therefore paid a salary. The corresponding order within the Macro will be: Call Ghosts() and return to the main module is used CallMain.

By using InputBox, MsgBox, Radio Buttom, 
Buttons, Check Box, etc. the auditor may interact with the application and make faster and more flexible achieving results, for example to detect Duplicates in a payroll, stated in that month you want to check:

In the example you want to detect duplicates in the corresponding payroll to July, pressing OK the application automatically detects duplicates and sample

The corresponding dialog box code is as follows:

\section{Sub Main}

\section{Dim Dlg1 As SUELDOS}

Button $=$ Dialog (Dlg1)

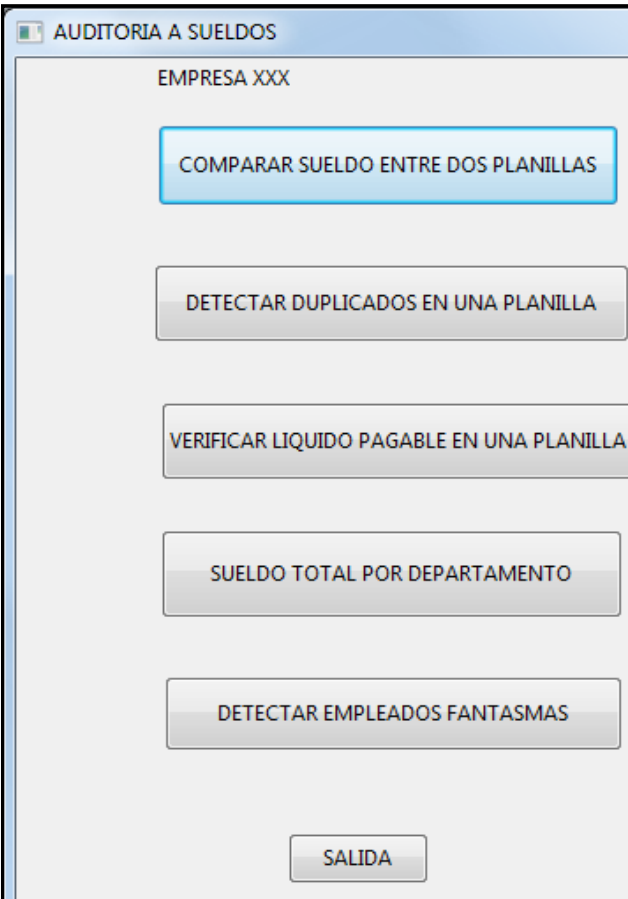

Fig. 1 The Auditor select the desired option.

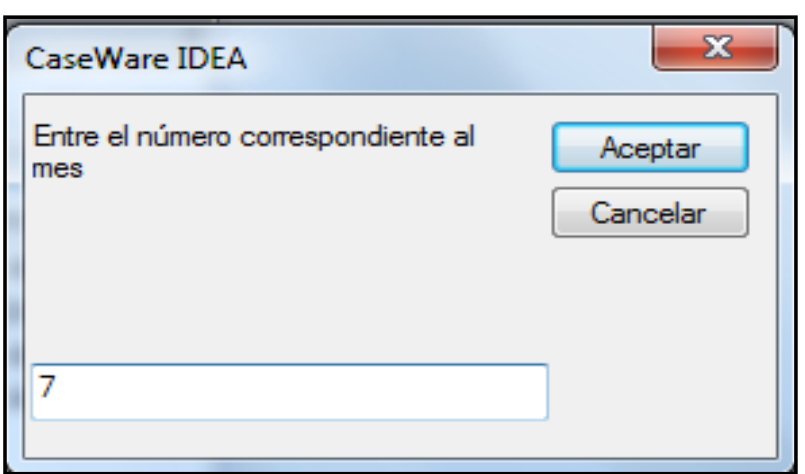

Fig. 2 Grasp the month (July).
If Button $=1$ Then

Paso $=0$

Call Mes()

ElseIf Button $=2$ Then

Client.CloseAll

Call Duplicado()

ElseIf Button $=3$ Then

Client.CloseAll

Call Neto()

ElseIf Button $=4$ Then

Client.CloseAll

Call TotalDpto()

Else

Client.Quit

Exit Sub

End If

\section{End Sub}

As explained above the Call orders call the functions entrusted to provide solutions to each of the tasks.

As part of the application of the CA in the financial area have verification of calculating interest, the macro is responsible for creating a virtual field that allows the recalculation of the interest determined by the financial institution. Virtual fields are not part of the original database, are created by the auditor with different purposes, in this case for the corresponding recalculation for a calculus of interests in a System Time Deposits Macro include the following formula:

@If( NIT <> 0 ; TASA_DE_INTERÉS_ANUAL / $36000 * \quad$ PLAZO * MONTO ; (TASA_DE_INTERÉS_ANUAL / $36000 *$ PLAZO * MONTO ) - 0.13* TASA_DE_INTERÉS_ANUAL / $36000 * \mathrm{PLAZO} * \mathrm{MONTO})$

In case of not having tax identification number is discounted $13 \%$.

The macro also includes the comparison of interest determined by the financial institution with interest calculated by the auditor; if they are different, there is a possibility or not of mistake by whoever is responsible for this task. As previously mentioned the 
macro can be extracted from History Software is not necessary to type it:

Another application is embodied in the FIU (financial intelligence units), in establishing rules for the prevention, detection, control and reporting of transactions allegedly linked to the laundering of illicit profits, it is determined to verify the customers who received US\$ 10,000 or more for three days, people may try to evade these controls making deposits in different accounts, even of different types such as savings accounts, fixed deposits, current accounts, etc. the macro developed to meet this control [14] includes the creation of a virtual field to work with a single currency, in this case US dollars, for this purpose formula is used:

\section{@if(MONEDA=1;MONTO/TIPO_DE_CAMBIO;} MONTO)

If the coin is 1 , it means that the transaction has been made in national currency, then the amount between the exchange rate is divided to convert to dollar opposite the transaction has been made in the original dollar amount remains.

Subsequently a summary or summarization of transactions by account and date is done and then the audit objective is verified. For example, to verify amounts superiors 10000 SUS for two days the macro includes the formula:

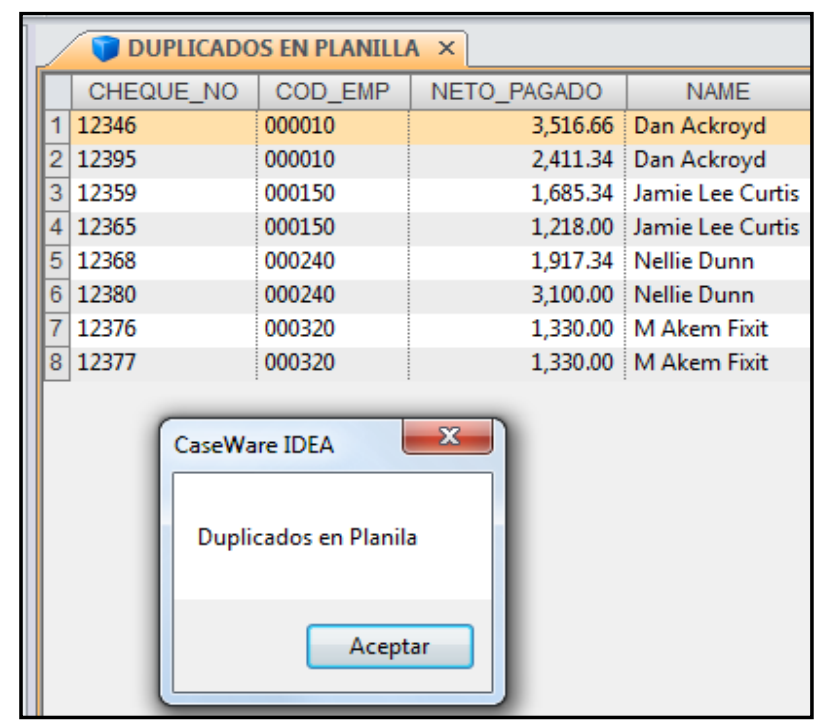

Fig. 3 Employees who appear 2 times on the score sheet.

\begin{tabular}{|c|c|c|c|}
\hline INTERÉS MAL CALCULA & & & \\
\hline \$ Exportar a 員吕 & 苞三 $=$ Filt & & \\
\hline datos & Fecha & Usuario & $\wedge$ \\
\hline Descripción de campo & & & \\
\hline Código de IDEAScript: & $\begin{array}{l}\text { Set db }= \\
\text { Set task } \\
\text { Set field } \\
\text { field.Na } \\
\text { field.De } \\
\text { field.Ty } \\
\text { field.Eg } \\
\text { PLAZO } \\
\text { MONTC } \\
\text { MONTC } \\
\text { field.De } \\
\text { task.Apt } \\
\text { task.Per } \\
\text { Set task } \\
\text { Set db } \\
\text { Set field }\end{array}$ & 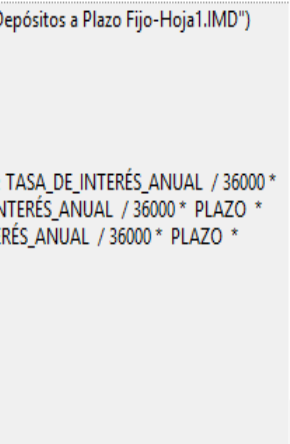 & \\
\hline
\end{tabular}

Fig. 4 Code corresponding to the macro script.

CLIENTE = @GetPreviousValue( " CLIENTE " ) .AND.

(MONTO_AUD_SUM_SUM

@GetPreviousValue( " MONTO_AUD_SUM_SUM " ) >= 10000) .OR.

$$
\text { CLIENTE = @GetNextValue( " CLIENTE " ) }
$$

.AND.

(MONTO_AUD_SUM_SUM

+@GetNextValue ( " MONTO_AUD_SUM_SUM ") $>=10000$ )

The execution of the macro allows a systematic control that fulfills the target for audit, issued a report where clients who have received amounts greater than \$ US for 1,2 or 3 days are shown:

Other applications related to financial area are control time attendance for treatment fits, savings, checking transactions during weekends and/or holidays, check transactions in overtime working hours, etc. [15].

\section{Benefits of Continuous Auditing}

(1) Improve administration workload with limited resources;

(2) It provides a deeper understanding of the processes taking place in the business;

(3) Make the Internal Audit be proactive and deliver better results;

(4) Reduce the time between audits;

(5) It allows the organization to determine the status 


\begin{tabular}{|c|c|c|c|c|c|c|}
\hline \multicolumn{6}{|c|}{ Un DIA.IMD $\times$ Depósitos de șS 10,000 du... $\times$} & \multirow[t]{2}{*}{$\nabla x$} \\
\hline & CLENTE $\triangle$ & NUM_DE_REGS1 & FECHA & MONTO_AUD_SUM_SUM & CRITERIO & \\
\hline 1 & 78 & & $208 / 00 / 2012$ & $10,357,14$ & Un día & \\
\hline 2 & 78 & & $208 / 02 / 2012$ & $10,357,14$ & Dos días & \\
\hline 3 & 78 & & $109 / 002 / 2012$ & 14.29 & Dos dias & \\
\hline 4 & 90 & & $402 / 02 / 2012$ & $11,146.59$ & Un dia & \\
\hline 5 & 1636 & & $101 / 002 / 2012$ & $8,587,00$ & Tres Días & \\
\hline 6 & 1636 & & $102 / 02 / 2012$ & 569.00 & Tres Días & \\
\hline 7 & 1636 & & $403 / 02 / 2012$ & $6,828.77$ & Tres Dias & \\
\hline 8 & 1956 & & $107 / 02 / 2012$ & $10,000.00$ & Un día & \\
\hline 9 & 2393 & & $103 / 02 / 2012$ & $16,251,00$ & Un día & \\
\hline 10 & 2752 & & $507 / 002 / 2012$ & $17,857,42$ & Un día & \\
\hline 11 & 2752 & & $308 / 02 / 2012$ & $22,154.57$ & Un día & \\
\hline 12 & 2752 & & $203 / 02 / 2012$ & $1,084.77$ & Dos días & \\
\hline 13 & 2752 & & $507 / 02 / 2012$ & $17,857,42$ & Dos dís & \\
\hline 14 & 2752 & & 3 & $22,154.57$ & Dos días & \\
\hline 15 & 2752 & & 4 09/02/2012 & $2,428.58$ & Dos dias & \\
\hline 16 & 2752 & & $301 / 02 / 2012$ & $1,508,62$ & Tres Días & \\
\hline 17 & 2752 & & $202 / 02 / 2012$ & $1,077.59$ & Tres Días & \\
\hline 18 & 2752 & & $203 / 02 / 2012$ & $1,084,77$ & Tres Días & \\
\hline 19 & 2752 & & $507 / 02 / 2012$ & $17,857,42$ & Tres Dias & \\
\hline 20 & 2752 & & $308 / 02 / 2012$ & $22,154.57$ & Tres Dias & \\
\hline 21 & 2752 & & 4 09/02/2012 & $2,428.58$ & Tres Días & \\
\hline 22 & 2976 & & $103 / 03 / 2012$ & $1,000,00$ & Dos dias & \\
\hline 23 & 2976 & & $104 / 03 / 2012$ & $9,000,00$ & Dos dias & \\
\hline 24 & 2976 & & $101 / 03 / 2012$ & 718.39 & Tres Días & \\
\hline 25 & 2976 & & $102 / 03 / 2012$ & $1,000,00$ & Tres Días & \\
\hline 26 & 2976 & & $103 / 03 / 2012$ & $1,000,00$ & Tres Días & \\
\hline 27 & 2976 & & $104 / 03 / 2012$ & $9,000,00$ & Tres Días & \\
\hline 28 & 8245 & & 2 201/02/2012 & $10,910,00$ & Un dia & \\
\hline 29 & 8259 & & $103 / 02 / 2012$ & $16,251,00$ & Un día & \\
\hline
\end{tabular}

Fig. 5 Results of the process.

of internal controls at any time;

(6) The Internal Audit becomes more independent and repeatable;

(7) You can make the job much faster;

(8) Data analysis is performed with greater consistency;

(9) It is easy to justify the actions to be performed based on the consistency of macros;

(10) A macro can be used by multiple users;

(11) The absence of a connoisseur of certain processes used does not mean it stops the work, because these processes are stored and organized in macros;

(12) Measure concretely an increase in the risk level of the entity, business unit and/or process;

(13) Increased coverage in the audit with the possibility of testing on $100 \%$ of the population;

(14) Reduced audit costs.

\section{Conclusions}

The CA is to conduct risk assessments and controls more frequently and better quality; these assessments can be performed in real time or shortly after these events that are verified.

When carrying out continuous auditing, management and other interested parties can have peace of mind about the proper functioning of their systems and processes, in contrast to the regular security provided by annual audits and quarterly reviews of financial statements and systems Company information.

At present the internal audit environment is a challenge within its functions which are to ensure risk mitigation, ensure that the controls operate accurate, efficient and timely manner, prevent and detect fraud, etc. To ensure compliance with its functions must have tools of information technology to facilitate their work, hence the importance of implementing processes Continuous Auditing in the company, however, is not as widespread use as it should, for a cause or other, in regions such as Latin America CAATs are not used in the magnitug to be, it may be for the cost of licenses, for lack of knowledge, not being included study plans of universities or other reason.

Using Macros or Scripts facilitates these processes that can be implemented without being specialist, but it is suggested that at least in an initial process working with multidisciplinary groups to ensure compliance with audit objectives, on the other hand in congresses, scientific events, etc. papers on these topics are made but focus on what the CA but not how to implement a more aggressive policy of training is needed especially in the universities so that students leave with the skills needed to apply these techniques in your work environment.

\section{References}

[1] David, C. 2005. "Royal Canadian MountedPolice (RCMP), "Global TechnologyAudit Guide Continuous Auditing: Implications for Assurance, Monitoring, and Risk Assessment.” IIA, Florida, USA.

[2] Evelio, H. P. "Application Techniques Computer Assisted Audit in the Prevention and Detection of Fraud.” Presented at the CISTI 2015, Aveiro, Portugal.

[3] EfrimBoritz, J., and Datardina, M. 2009. “Monitoring, 
Auditing and Assurance Continuous: CAATs for the XXI Century.” University of Waterloo, Canada.

[4] Caseware RCM Inc. 2010. "Continuous Auditing." Overview of the solution.Ottawa, Canada.

[5] Schnider, M. F., and Nessier, P. G. 2014. "Continuous Auditing. Paradigm Permanent Change.” V Jornadas sobre control interno y riesgos en entidades financieras, Entre Rios, Argentina.

[6] Pedrosa, I., Laureano, R. M. S., and Costa, C. J. 2015. "Motivations of Auditors for the Use of Information Technology in Their Profession: Application to Auditors." Revista Ibérica de Sistemas e Tecnologías de Información 15: 101-18.

[7] Pedrosa, I., Costa, C. J., and Laureano, R. M. S. 2015. "Motivations and Limitations on the Use of Information Technologyonstatutoryauditors' Work: Anexploratory Study.” In 2015 Proceedings - 10th Iberian Conference on Information Systems and Technologies, 1132-37.

[8] Mueller, J. P. 2011. Matering IDEAScript, the Definite Guide. New Jersey: Wiley\&Sons, Inc..

[9] Jolly, M. J. R. 2012. "Planning and Implementation of
Continuous Auditing.” BDO Consulting, Panama.

[10] Soliz. G. 2010. "Data Analysis Tools for Managing Fraud." $4^{\circ}$ Congreso de Prevención de Fraude y Seguridad, Bogotá, Colombia.

[11] Pedrosa, I., Costa, C. J., and Laureano, R. M. S. 2015. "Use of Information Technology on Statutory Auditors' Work: New profilesbeyondSpreadsheets' Users.” In CISTI Proceedings-10th IberianConferenceonInformationSystems and Technologies, 774-9.

[12] “Tutorial de IDEA 2010.” Capítulo 3. Procedimientos Iniciales, Caseware IDEA Inc, Toronto, Canadá, 2016

[13] Hernandez, P. E. 2016. "Continuous Auditing to Manage Risks in Payroll Salary.” CISTI, Gran Canaria, Espana.

[14] Emilio, N. 2015. "How to Increase Your Productivity with Continuous Controls.” PMN Consultores, CIGRAS, Montevideo, Uruguay.

[15] Pablos, C. D., Lopez, J., Romo, S., and Medina, S. 2011. "Transformation of Organization and Information Systems Company.” Capítulo 5, pag. 355, Madrid, Espana. 